\title{
The Effect of Steroids and Nucleotides on Solubilized Bilirubin Uridine Diphosphate-Glucuronyltransferase
}

\author{
By B. P. F. ADLARD* AND G. H. LATHE \\ Department of Chemical Pathology, University of Leeds, Leeds LS2 9NL, U.K.
}

(Received 16 March 1970)

\begin{abstract}
1. It was confirmed that bilirubin glucuronyltransferase can be obtained in solubilized form from rat liver microsomes. 2. Michaelis-Menten kinetics were not followed by the enzyme with bilirubin as substrate when the bilirubin/albumin ratio was varied. High concentrations of bilirubin were inhibitory. 3. The $K_{m}$ for UDPglucuronic acid at the optimum bilirubin concentration was $0.46 \mathrm{~mm}$. 4. Low concentrations of $\mathrm{Ca}^{2+}$ were inhibitory in the absence of $\mathrm{Mg}^{2+}$ but stimulatory in its presence; the converse applied for EDTA. 5. UDP- $N$-acetylglucosamine and UDP-glucose enhanced conjugation by untreated, but not by solubilized microsomes. 6. The apparent 9.5-fold increase in activity after solubilization was probably due to the absence of UDP-glucuronic acid pyrophosphatase activity in the solubilized preparation. 7. The activation of solubilized enzyme activity by ATP was considered to be a result of chelation of inhibitory metal ions. 8. The solubilized enzyme activity was inhibited by UMP and UDP. The effect of UMP was not competitive with respect to UDP-glucuronic acid. 9. A number of steroids inhibited the solubilized enzyme activity. The competitive effects of stilboestrol, oestrone sulphate and $3 \beta$-hydroxyandrost-5-en-17-one, with respect to UDP-glucuronic acid, may be explained on an allosteric basis.
\end{abstract}

The enzyme UDP-glucuronate glucuronyltransferase (EC 2.4.1.17), usually referred to as 'glucuronyltransferase' catalyses the transfer of glucuronic acid from UDP-glucuronic acid to an aglycone, with formation of a glucuronide and UDP. There is considerable evidence [summarized by Dutton (1966)] for several glucuronyltransferases, with varying specificity for different aglycones, in mammalian liver.

Because of its clinical implications the enzyme activity with bilirubin as substrate has attracted particular attention. Initial reports (Isselbacher, Chrabas \& Quinn, 1962; Tomlinson \& Yaffe, 1966) indicated that attempts to solubilize liver microsomes by a variety of procedures resulted in partial or complete loss of bilirubin glucuronyltransferase activity. Halac \& Reff (1967) reported, however, that a relatively stable, solubilized enzyme activity was obtained by dialysis of rat liver microsomes against alkaline EDTA followed by treatment with deoxycholate.

Several workers have examined the effects of steroids (Hsia, Riabov \& Dowben, 1963; Jones, 1964 ; Bevan, Holton \& Lathe, 1965) and nucleo-

* Present address: Department of Child Health, Clinical Sciences Building, York Place, Manchester 13, U.K. tides (Pogell \& Leloir, 1961; Halac \& Reff, 1967; Lester, 1968) on the (non-solubilized) glucuronyltransferase activity of microsomes. Many steroids were inhibitory; nucleotides apparently activated (e.g. UDP- $N$-acetylglucosamine) or inhibited (e.g. UMP). Several authors speculated on the possible regulatory role of steroids and nucleotides in bilirubin metabolism in vivo particularly in the newborn infant where glucuronyltransferase activities are low (Lathe \& Walker, 1958a).

UDP-glucuronic acid, the co-substrate in the glucuronyltransferase reaction, may also be metabolized by a nucleotide diphosphate sugar pyrophosphatase (Ginsburg, Weissbach \& Maxwell, 1958; Conney \& Burns, 1961) forming UMP and glucuronic acid 1-phosphate. UDP-glucuronic acid pyrophosphatase is present in both the nuclear (Schliselfeld, van Eys \& Touster, 1965) and the microsomal (Ogawa, Sawada \& Kawada, 1966) fractions of rat liver and is inhibited by a variety of nucleotides including UDP-glucose, UDP- $N$ acetylglucosamine and ATP.

We have used a modification of the technique described by Halac \& Reff (1967) to solubilize bilirubin glucuronyltransferase from rat liver and have investigated the influence of steroids and nucleotides on the enzyme activity. 


\section{MATERIALS AND METHODS}

Animals. Male Hooded rats $(200-400 \mathrm{~g})$ were used and were maintained on M.R.C. 41B diet, and water ad libitum. Animals were killed by cervical dislocation.

Chemicals. UDP-glucuronic acid, UDP-glucose and UDP- $N$-acetylglucosamine were obtained from C. F. Boehringer und Soehne G.m.b.H., Mannheim, Germany. Other nucleotides, most steroids and $5^{\prime}$-nucleotidase were from the Sigma Chemical Co., St Louis, Mo., U.S.A. $3 \beta, 16 \alpha$-Dihydroxyandrost-5-en-17-one was a gift from Professor W. Klyne, M.R.C. Steroid Reference Collection. Bilirubin, stilboestrol and general chemicals were from British Drug Houses Itd., Poole, Dorset, U.K.

Preparation of liver microsomal fraction. The method of Schneider \& Hogeboom (1950) was used.

Preparation of a solubilized liver microsomal fraction. The method of Halac \& Reff (1967) was used, with two modifications: $(a)$ the EDTA-dialysis step was omitted since, in two experiments where dialysis was carried out as described by Halac \& Reff (1967), no significant activation of bilirubin glucuronyltransferase was observed; (b) Sephadex G-25 (not G-200) was used for removal of deoxycholate from the solubilized preparation.

All operations were performed at $0-4^{\circ} \mathrm{C}$. A rat liver $(10-15 \mathrm{~g})$ was homogenized in $0.01 \mathrm{M}$-tris $-0.14 \mathrm{M}-\mathrm{KCl}$ (pH 8.0), with a Teflon-glass homogenizer [12 strokes at $1100 \mathrm{rev} . / \mathrm{min}$ as described by Aldridge, Emery \& Street (1960)] to produce a $20 \%(\mathrm{w} / \mathrm{v})$ homogenate which was immediately centrifuged at $2000 \mathrm{~g}(15 \mathrm{~min})$. To the resulting supernatant was added $0.7 \mathrm{vol}$. of saturated $\left(\mathrm{NH}_{4}\right)_{2} \mathrm{SO}_{4}$ solution [containing $1.0 \mathrm{ml}$ of $\mathrm{NH}_{3}$ (sp. gr. $0.88) / 1$ and $1.0 \mathrm{~nm}$-EDTA (sodium salt)]. After stirring (10 min) centrifugation was carried out at $2000 \mathrm{~g}_{\text {av. }}$. (10 min). The precipitate was resuspended in $30 \mathrm{ml}$ of $0.01 \mathrm{~mm}$-tris-0.14 mM-KCl (pH8.0), and the suspension was centrifuged at $40000 \mathrm{~g}_{\text {av }}(90 \mathrm{~min})$. The resulting microsomal pellet was homogenized (10 strokes) in $25 \mathrm{ml}$ of $0.3 \%(w / v)$ sodium deoxycholate and $1.0 \mathrm{~mm}$-EDTA (pH 8.0). Further centrifugation was carried out at $40000 \mathrm{~g}_{\text {av. }}(90 \mathrm{~min})$. The clear supernatant was added to the top of a Sephadex G-25 column $(20 \mathrm{~cm} \times 2.5 \mathrm{~cm})$, prepared after equilibration with excess of $0.05 \mathrm{M}$-tris in 1.0 mM-EDTA (pH8.0). Elution was carried out with $0.05 \mathrm{M}$-tris in $1.0 \mathrm{~mm}$-EDTA (pH8.0) and the orangeyellow part of the eluate, which had been found to contain transferase, was collected and stored at $4^{\circ} \mathrm{C}$.

Determination of bilirubin glucuronyltransferase activity. The method was based on those of Lathe \& Walker (1958a) and Halac \& Reff (1967) the substrate, bilirubin, being provided in adult male human serum. Incubation mixtures (total vol. $1.25 \mathrm{ml}, \mathrm{pH} 7.9$ ) were prepared in tubes kept in ice and had the following composition: bilirubin (0.1 mM), UDP-glucuronic acid ( $0.25 \mathrm{~mm}$ except where stated otherwise), serum $(5.8 \%, \nabla / v), \mathrm{Mg}^{2+}$ $(5.0 \mathrm{mM})$, microsomal preparation $(0.5-1.5 \mathrm{mg}$ of protein), $10 \mathrm{~mm}$-tris-0.14 M-KCl (pH 8.0). In some experiments $10 \%(v / v)$ dimethylsulphoxide rather than $5.8 \%(v / v)$ serum was used as the incubation medium. In $10 \%$ dimethylsulphoxide the optimum bilirubin concentration was about $0.1 \mathrm{~mm}$. Steroids were added to tubes as methanolic solutions which were evaporated in a current of $\mathrm{N}_{2}$ before adding the incubation mixture. Incubation $\left(10 \mathrm{~min}, 37^{\circ} \mathrm{C}\right)$ was carried out with shaking (100 cycles/ min) in an atmosphere of $N_{2}$. After incubation, tubes were placed in ice-water ( $5 \mathrm{~min})$ and direct-reacting bilirubin was determined by the method of Lathe \& Walker (1958a).

All incubations were done in duplicate. Blanks contained no UDP-glucuronic acid. Enzyme activity was expressed as $\mu \mathrm{g}$ of bilirubin conjugated/h per $\mathrm{mg}$ of protein. Protein was determined by the method of Lowry, Rosebrough, Farr \& Randall (1951). Although the variation between different animal preparations was large the 'within batch' coefficient of variation was 3.5 in a series of ten replicates. Differences from controls of more than $10 \%$ were regarded as significant.

Determination of UDP-glucuronic acid breakdown. UDP-glucuronic acid $(250 \mu \mathrm{mol})$ was incubated for $20 \mathrm{~min}$ at $37^{\circ} \mathrm{C}$, in $0.5 \mathrm{ml}$ of $10 \mathrm{~mm}$-tris $-0.14 \mathrm{~mm}-\mathrm{KCl}$ at $\mathrm{pH} 8.0$, with untreated or solubilized microsomes equivalent to $40 \mathrm{mg}$ of liver. In experiments with solubilized microsomes $5 \mu \mathrm{g}$ of snake venom $5^{\prime}$-nucleotidase was added as the activity of this enzyme was decreased by the solubilization. Each determination was done in duplicate, $\mathbf{P}_{\mathbf{1}}$ being determined in a trichloroacetic acid supernatant according to the method described by Fiske \& Subbarow (1925).

\section{RESULTS}

Glucuronyltransferase activity in solubilized and untreated microsomes. The glucuronyltransferase activity in solubilized microsomes was stable for about one week; after this period activity began to decline. The quantity of bilirubin conjugate formed was proportional to both time of incubation $(0-20 \mathrm{~min})$ and the amount of microsomal protein $(0.2-2.5 \mathrm{mg})$. No direct-reacting bilirubin was formed by incubation at $4^{\circ} \mathrm{C}$ or with an enzyme preparation previously heated in a boiling-water bath for 1 min.

The transferase activity was about tenfold greater in solubilized than in untreated microsomes (Table 1) despite the higher UDP-glucuronic acid concentration used with the latter. This increase in specific activity on solubilization was not due to

Table 1. Glucuronyltransferase activity of solubilized and untreated rat liver microsomes

Each value is the mean ( \pm S.D.). The incubation medium was $5.8 \%(v / v)$ serum and $0.1 \mathrm{~mm}$-bilirubin.

Microsomal preparation

Solubilized

Untreated
Concentration of

UDP-glucuronic acid (mM)

0.25

0.50
Glucuronyltransferase activity

( $\mu \mathrm{g} / \mathrm{h}$ per $\mathrm{mg}$ of protein)

$28.5 \pm 12.7$

$3.0 \pm 0.9$
No. of rats

8

4 
loss of protein since deoxycholate released $85 \%$ of microsomal protein.

Variation of glucuronyltransferase activity with substrate concentration. The optimum bilirubin concentration for the solubilized enzyme was about $0.2 \mathrm{~mm}$. Higher concentrations were inhibitory. Plots of $1 / v$ versus $1 /[\text { bilirubin }]^{2}$ (Fig. 1) were linear over the range $0.025-0.2 \mathrm{mM}$.

Double reciprocal plots of activity against UDP-glucuronic acid concentration were linear (for example, Figs. 4, 6, 7 and 8). The $K_{m}$ for UDP-glucuronic acid (at a bilirubin concentration of $0.1 \mathrm{~mm}$ ) in the presence of serum was $0.46 \mathrm{~mm}$ (mean of five preparations).

Variation of glucuronyltransferase activity with $\mathrm{Mg}^{2+}$ and $\mathrm{Ca}^{2+}$ concentrations. In the presence of undialysed serum (Fig. 2) the optimum $\mathrm{Mg}^{2+}$

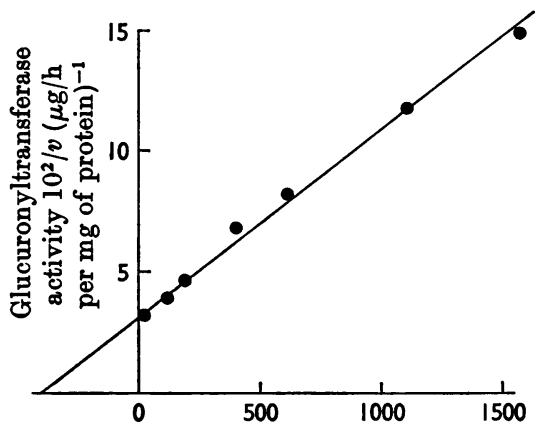

[Bilirubin $]^{-2}(\mathbf{m M})^{-2}$

Fig. 1. Double-reciprocal plot of solubilized glucuronyltransferase activity with [bilirubin] ${ }^{2}$. The serum concentration was constant at $5.8 \%(\nabla / v)$. concentration was approximately $5 \mathrm{~mm}$. In the absence of added $\mathrm{Mg}^{2+}$ some conjugation occurred, when undialysed serum was present, but there was no activity when dimethylsulphoxide was used in the medium in place of serum (Fig. 2).

In the absence of $\mathbf{M g}^{2+}$, low concentrations of $\mathrm{Ca}^{2+}$ enhanced the bilirubin glucuronyltransferase activity (Fig. $3 a$ ) whereas EDTA was inhibitory. At the optimum $\mathrm{Mg}^{2+}$ concentration $\mathrm{Ca}^{2+}$ was inhibitory (Fig. 3b); under these conditions

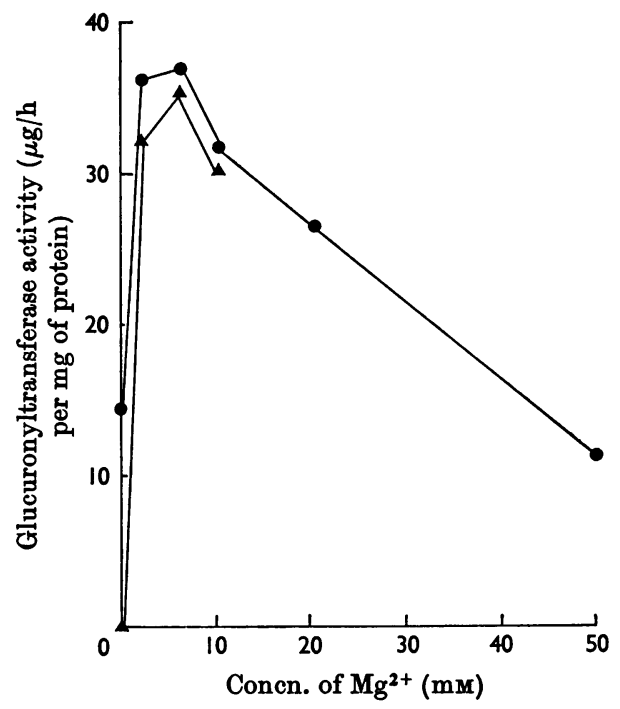

Fig. 2. Variation of solubilized glucuronyltransferase activity with concentration of $\mathrm{Mg}^{2+}$. The incubation medium was $0.1 \mathrm{~mm}$-bilirubin and either $5.8 \%(\mathrm{v} / \mathrm{v})$ serum (๑) or $10 \%(v / v)$ dimethylsulphoxide $(\Delta)$.

Table 2. Effect of nucleotides on the glucuronyltransferase activity of solubilized rat liver microsomes

The activity in the presence of nucleotides is expressed as a percentage of that under standard conditions (5.8\% serum). Values in parentheses are the number of preparations for which the mean is given.

\section{Addition}

UDP- $N$-acetylglucosamine UDP- $N$-acetylglucosamine UDP- $N$-acetylglucosamine UDP-glucose UDP-glucose

ATP

ATP

ADP

AMP

$3^{\prime}: 5^{\prime}$-cyclic-AMP

UTP

UDP

UMP

\section{Concentration (mM)}

0.25

0.5

1.0

0.5

1.0

0.5

1.0

1.0

1.0

1.0

1.0

1.0

1.0
Glucuronyltransferase activity ( $\mu \mathrm{g} / \mathrm{h}$ per $\mathrm{mg}$ of protein)

$$
\begin{array}{r}
102(6) \\
98(1) \\
103(1) \\
100(1) \\
99(1) \\
120(4) \\
140(5) \\
120(2) \\
108(2) \\
118(2) \\
96(2) \\
76(3) \\
70(2)
\end{array}
$$



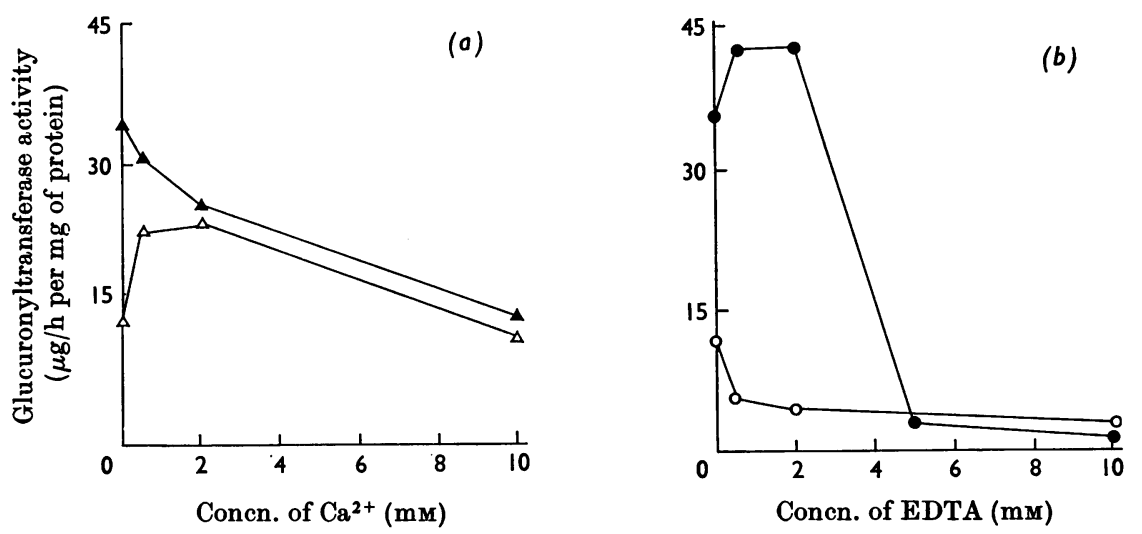

Fig. 3. Variation of solubilized glucuronyltransferase activity with $\mathrm{Ca}^{2+}$ and EDTA concentration in presence of ( $5 \mathrm{mM})$ and absence of $\mathrm{Mg}^{2+}$. (a) $\triangle, \mathrm{Ca}^{2+}$ without $\mathrm{Mg}^{2+} ; \Delta, \mathrm{Ca}^{2+}$ with $\mathrm{Mg}^{2+}$. (b) $\mathrm{O}$, EDTA without $\mathrm{Mg}^{2+}$; , EDTA with $\mathrm{Mg}^{2+}$.

EDTA stimulated at low, but inhibited at high, concentrations.

Effect of nucleotides on the solubilized glucuronyltransferase activity. Neither UDP- $N$-acetylglucosamine nor UDP-glucose affected the solubilized transferase activity (Table 2). Activity was stimulated by adenosine phosphates, the degree of stimulation decreasing in the order ATP, ADP , $3^{\prime}: 5^{\prime}$-cyclicAMP, AMP. Of the three uridine phosphates studied UDP and UMP were significantly inhibitory.

The effect of UMP was examined with variation of the UDP-glucuronic acid concentration, and expressed as a double reciprocal (Lineweaver \& Burk, 1934) plot (Fig. 4). UMP did not show purely competitive inhibition with respect to UDPglucuronic acid. Similar results were obtained with UDP. For comparison Table 3 shows the results of a typical experiment with untreated microsomes. UDP- $N$-acetylglucosamine, UDP-glucose and ATP all enhanced conjugation.

Preincubation experiments. To determine how much of the apparent stimulation by nucleotides was due to inhibition of UDP-glucuronic acid breakdown, microsomal preparations were preincubated with UDP-glucuronic acid (and UDP$\mathrm{N}$-acetylglucosamine) after which transferase activity was assessed (Table 4). In two experiments (A and B) with untreated microsomes the apparent transferase activity was decreased by approximately $50 \%$ when UDP-glucuronic acid (alone) was added before, rather than after, preincubation. The simultaneous presence of UDP- $N$-acetylglucosamine blocked this. In two experiments (C and D) with solubilized preparations, the time at which UDP-glucuronic acid was added did not significantly affect the enzyme activity. Since UDP-

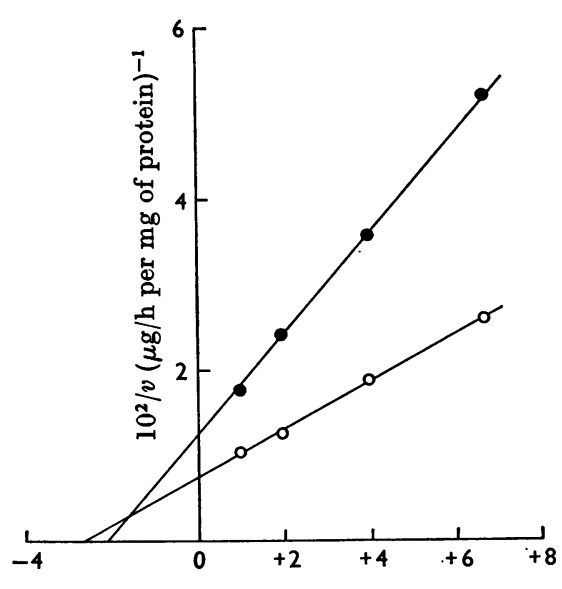

[UDP-glucuronic acid] $]^{-1}(\mathrm{mM})^{-1}$

Fig. 4. Double-reciprocal plot showing inhibition of glucuronyltransferase by UMP $(2.0 \mathrm{mM})$ as a function of UDP-glucuronic acid concentration. $\bigcirc$, No UMP; $\bullet$, UMP added. The incubation medium was $5.8 \%(\mathrm{v} / \mathrm{v})$ serum and $0.1 \mathrm{~mm}$-bilirubin.

glucuronic acid was added at less than saturating concentrations these results were interpreted as indicating that UDP-glucuronic acid was broken down (presumably by UDP-glucuronic acid pyrophosphatase) by untreated but not by solubilized microsomes. This was confirmed by determination of inorganic phosphate generated from nucleotide. In two experiments with untreated microsomes 68 and $96 \%$ of the UDP-glucuronic acid was degraded. With solubilized microsomes, to which $5^{\prime}$-nucleo- 
Table 3. Effect of nucleotides on the glucuronyltransferase activity of untreated rat liver microsomes

The incubation medium was $5.8 \%(\mathrm{v} / \mathrm{v})$ serum. The UDP-glucuronic acid concentration was $0.5 \mathrm{~mm}$.

Addition Concentration (mM)

None

UDP- $N$-acetylglucosamine

ATP

UDP- $N$-acetylglucosamine

+ ATP

UDP-glucose

$\overline{0.25}$
0.5
0.25
0.5
1.0

Glucuronyltransferase activity

$(\mu \mathrm{g} / \mathrm{h}$ per $\mathrm{mg}$ of protein)

1.8
7.3
3.4
2.5
5.7

Tuble 4. Effect of preincubation with or without UDP-glucuronic acid (or UDP-N-acetylglucosamine) on the subsequent glucuronyltransferase activity of solubilized and untreated microsomes

The microsomal preparations were preincubated $\left(10 \mathrm{~min}, 37^{\circ} \mathrm{C}\right.$, in air) without bilirubin. UDP-glucuronic acid and UDP- $N$-acetylglucosamine were added to a final concentration of $0.25 \mathrm{mM}$ at the times indicated. Bilirubin was added after preincubation. The incubation medium was $5.8 \%(v / v)$ serum.

\begin{tabular}{lllr}
$\begin{array}{l}\text { Microsomal } \\
\text { preparation }\end{array}$ & \multicolumn{1}{c}{$\begin{array}{c}\text { Nucleotide(s) added } \\
\text { before preincubation }\end{array}$} & \multicolumn{1}{c}{$\begin{array}{c}\text { Nucleotide(s) added } \\
\text { after preincubation }\end{array}$} & $\begin{array}{r}\text { Glucuronyltransferas } \\
(\mu \mathrm{g} / \mathrm{h} \text { per } \mathrm{mg}\end{array}$ \\
A (untreated) & None & UDP-glucuronic acid & 4.0 \\
& UDP-glucuronic acid & None & 1.8 \\
B (untreated) & None & UDP-glucuronic acid & 3.8 \\
& UDP-glucuronic acid & None & 2.0 \\
& UDP-glucuronic acid & UDP-acetylglucosamine & 3.6 \\
& None & UDP-glucuronic acid & 9.4 \\
& UDP-glucuronic acid & +UDP- $N$-acetylglucosamine & \\
& +UDP- $N$-acetylglucosamine & None & 9.2 \\
C (solubilized) & None & UDP-glucuronic acid & 48.8 \\
& UDP-glucuronic acid & None & 48.0 \\
D (solubilized) & None & UDP-glucuronic acid & 15.7 \\
& UDP-glucuronic acid & None & 15.2
\end{tabular}

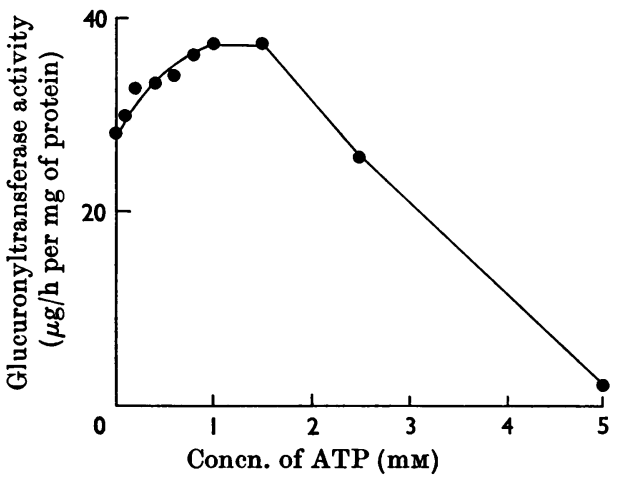

Fig. 5. Variation of solubilized glucuronyltransferase activity with concentration of ATP. The incubation medium was $5.8 \%(v / v)$ serum, and $0.1 \mathrm{~mm}$-bilirubin.

tidase was added since solubilization greatly decreased the native enzyme content, only 2 and $<1 \%$ of the nucleotide was destroyed.
Stimulation of solubilized glucuronyltransferase activity by ATP. The effects of ATP on the transferase activity resembled those of EDTA. The greatest stimulation by ATP occurred at a concentration of 1-2 mM (Fig. 5). Higher concentrations were inhibitory. ATP (1.0 mM) stimulated in the presence of $\mathrm{Mg}^{2+}$ and inhibited in its absence (Table 5, Expt. A; cf. Fig. 3). The stimulatory effects of ATP and EDTA were not additive (Table 5, Expt. B). Both ATP and EDTA (1 mM) were inhibitory when serum was excluded by adding bilirubin in dimethylsulphoxide (Table 5, Expt. C).

Effect of steroids on the solubilized glucuronyltransferase activity. Several steroids (and stilboestrol) were inhibitory (Table 6). The inhibitory activities did not vary appreciably between different preparations. For example the activities in the presence of $3 \beta$-hydroxyandrost-5-en-17-one $(0.25 \mathrm{~mm})$ were $53,59,59$ and $55 \%$ in four preparations. Three of the more potent inhibitors (oestrone sulphate, stilboestrol and $3 \beta$-hydroxyandrost-5en-17-one) were competitive inhibitors with respect to UDP-glucuronic acid (Figs. 6, 7 and 8). 
Table 5. Effect of $\mathrm{Mg}^{2+}, A T P$ and $E D T A$ on the glucuronyltransferase activity of solubilized rat liver microsomes

A different preparation was used for each experiment. The values in parentheses refer to the enzyme activity as a percentage of the corresponding activity in the absence of ATP or EDTA.

\begin{tabular}{|c|c|c|c|c|c|}
\hline Experiment & $\begin{array}{c}\text { Incubation } \\
\text { medium }\end{array}$ & $\begin{array}{l}\text { Concn. of } \\
\mathrm{Mg}^{2+}(\mathrm{mM})\end{array}$ & $\begin{array}{l}\text { Concn. of } \\
\operatorname{ATP}(\mathrm{mM})\end{array}$ & $\begin{array}{c}\text { Concn. of } \\
\text { EDTA (mM) }\end{array}$ & $\begin{array}{l}\text { Glucuronyltransferase } \\
\text { activity } \\
\text { ( } \mu \mathrm{g} / \mathrm{h} \text { per mg of protein) }\end{array}$ \\
\hline \multirow[t]{4}{*}{$\mathbf{A}$} & $5.8(v / v)$ serum & - & - & - & $14.8(100)$ \\
\hline & & - & 1.0 & - & $11.5 \quad(78)$ \\
\hline & & 5.0 & - & - & $33.6(100)$ \\
\hline & & 5.0 & 1.0 & - & $41.7(124)$ \\
\hline \multirow[t]{6}{*}{ B } & $5.8(v / v)$ serum & 5.0 & - & - & $19.2(100)$ \\
\hline & & 5.0 & 1.0 & - & $24.4(127)$ \\
\hline & & 5.0 & 1.5 & 一 & $22.6(118)$ \\
\hline & & 5.0 & - & 0.5 & 23.7 (123) \\
\hline & & 5.0 & 一 & 1.5 & $22.6(118)$ \\
\hline & & 5.0 & 1.0 & 0.5 & $22.9(119)$ \\
\hline \multirow[t]{6}{*}{ C } & $5.8(v / v)$ serum & 5.0 & - & - & $43.2(100)$ \\
\hline & & 5.0 & 1.0 & - & $60.6(140)$ \\
\hline & & 5.0 & - & 1.0 & $53.4(124)$ \\
\hline & $10 \%(v / v)$ & 5.0 & - & - & $56.2(100)$ \\
\hline & dimethylsulphoxide & 5.0 & 1.0 & - & $36.6(65)$ \\
\hline & & 5.0 & - & 1.0 & $31.8 \quad(57)$ \\
\hline
\end{tabular}

Table 6. Effect of steroids on the glucuronyltransferase activity of solubilized rat liver microsomes

The incubation medium was $5.8 \%(v / v)$ serum. Each activity was calculated as a percentage of the activity obtained in the same experiment with no additions, and is expressed as the mean of activities of a number (given in parentheses) of preparations.

\begin{tabular}{lcc}
\multicolumn{1}{c}{ Addition } & Concn. (mM) & $\begin{array}{c}\text { Glucuronyltransferase } \\
\text { activity (\%) }\end{array}$ \\
Oestrone & 0.25 & $78(2)$ \\
Oestrone sulphate & 0.25 & $34(2)$ \\
Oestradiol & 0.25 & $72(2)$ \\
Oestriol & 0.25 & $86(2)$ \\
Stilboestrol & 0.05 & $38(2)$ \\
3 $\beta$-hydroxyandrost-5-en-17-one & 0.05 & $80(2)$ \\
3 $\beta$-hydroxyandrost-5-en-17-one & 0.25 & $56(4)$ \\
3 $\beta$-hydroxyandrost-5-en-17-one & 0.25 & $80(2)$ \\
sulphate & & \\
3 $\beta, 16 \alpha$-dihydroxyandrost-5-en- & 0.25 & $79(2)$ \\
17-one & & \\
Pregnane-3 $\alpha, 20 \alpha$-diol & 0.25 & $102(2)$ \\
Pregnane-3 $\alpha, 20 \beta$-diol & 0.25 & $96(2)$
\end{tabular}

\section{DISCUSSION}

We have confirmed the findings by Halac \& Reff (1967) that a highly active, reasonably stable, bilirubin glucuronyltransferase preparation, that is not sedimented at $40000 \mathrm{~g}_{\mathrm{av}}$. for $90 \mathrm{~min}$, can be obtained from rat liver microsomes with $0.3 \%$ deoxycholate. We omitted dialysis against EDTA and obtained a similar conjugation $(28.5 \mu \mathrm{g} / \mathrm{h}$ per $\mathrm{mg}$ of protein; Table 1) to Halac \& Reff (1967).

Since this work was completed Graham \& Wood (1969) have reported that the activity of $p$-nitrophenol glucuronyltransferase of guinea-pig liver is dependent on phospholipid. Treatment of microsomes with phospholipase $A$ or $\mathrm{C}$ inactivated the transferase but this could be reversed, in part, by adding phospholipid micelles. If this is confirmed for the system we studied, it implies that phospholipid micelles are present in the $40000 g_{\text {av. }}$ supernatant.

Tomlinson \& Yaffe (1966), Flodgaard \& Brodersen (1967) and Halac \& Reff (1967) worked with microsomes and bilirubin combined with albumin. They obtained linear plots of $1 / v$ versus $1 /$ [bilirubin]. In Fig. $11 / v$ for soluble enzyme was linear with $1 /[\text { bilirubin }]^{2}$. We suggest that this unusual 


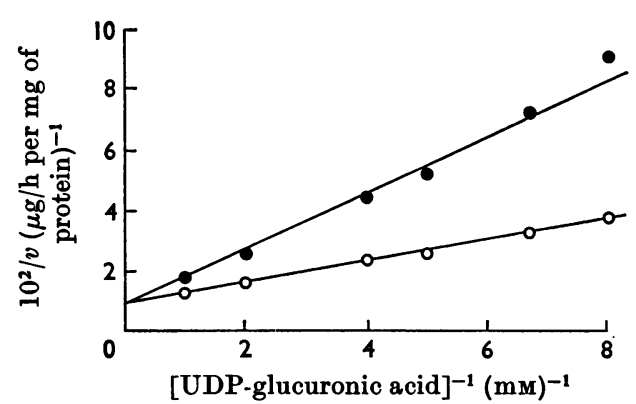

Fig. 6. Double-reciprocal plot showing inhibition of glucuronyltransferase by oestrone sulphate $(0.15 \mathrm{mM})$ as a function of UDP-glucuronic acid concentration. $O$, No oestrone sulphate; $\bullet$, oestrone sulphate added. The incubation medium was $5.8 \%(\mathrm{v} / \mathrm{v})$ serum and $0.1 \mathrm{~mm}$ bilirubin.

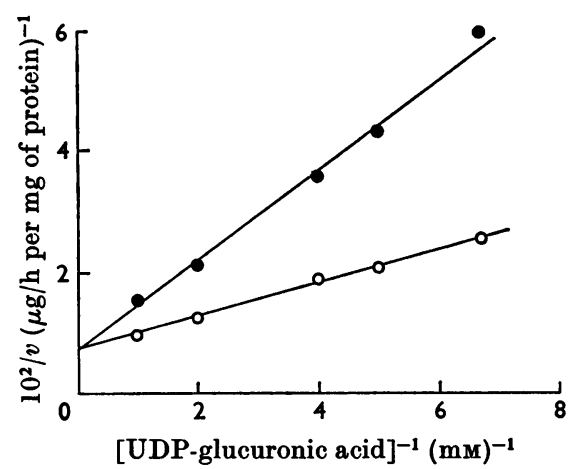

Fig. 7. Double-reciprocal plot showing inhibition of glucuronyltransferase by stilboestrol $(0.05 \mathrm{mM})$ as a function of UDP-glucuronic acid concentration. $O$, No stilboestrol; $\bullet$, stilboestrol added. Theincubation medium was $5.8 \%(\mathrm{v} / \mathrm{v})$ serum and $0.1 \mathrm{~mm}$-bilirubin.

behaviour was due to variation of the bilirubin/ albumin ratio (the serum concentation was kept constant). At bilirubin concentrations below $40 \mathrm{~mm}$ where the molar ratio to albumin was less than 1 a smaller proportion of the substrate would have been available to the enzyme. Solubilized glucuronyltransferase activity was inhibited by concentrations of bilirubin above about $0.3 \mathrm{~mm}$. This has also been observed with rabbit liver microsomes (Tomlinson \& Yaffe, 1966).

The enzyme activity obeyed Michaelis-Menten kinetics with respect to UDP-glucuronic acid. At optimum bilirubin concentrations, it had a $K_{m}$ for UDP-glucuronic acid $(0.46 \mathrm{mM})$ which was similar to that reported for untreated rat liver microsomes (Van Roy \& Heirwegh, 1968) and for the EDTAactivated preparation (Halac \& Reff, 1967).

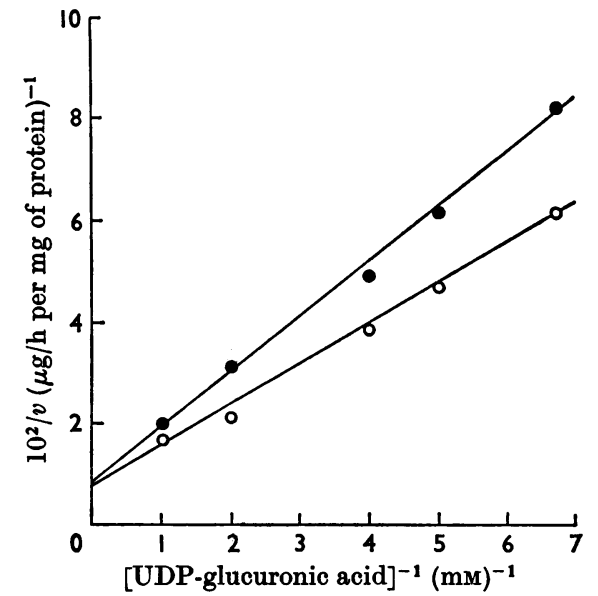

Fig. 8. Double-reciprocal plot showing inhibition of glucuronyltransferase by $3 \beta$-hydroxyandrost-5-en-17-one $(0.1 \mathrm{mM})$ as a function of UDP-glucuronic acid concentration. $O$, No steroid; $\bullet$, steroid added. The incubation medium was $5.8 \%(v / v)$ serum and $0.1 \mathrm{~mm}$-bilirubin.

In order to examine the requirements of the soluble transferase for divalent cations, a system with $10 \%(\mathrm{v} / \mathrm{v})$ dimethylsulphoxide was devised, as the use of serum would have involved about $0.1 \mathrm{~mm}-\mathrm{Ca}^{2+}$ and $0.01 \mathrm{~mm}-\mathrm{Mg}^{2+}$. At high bilirubin concentrations the two systems gave similar rates of conjugation. At low concentrations $(<0.1 \mathrm{~mm})$ it was difficult to compare them, because of the lower $K_{m}$ in dimethylsulphoxide and an excessively high percentage conjugation. In dimethylsulphoxide the enzyme had an absolute requirement for $\mathrm{Mg}^{2+}$ (Fig. 2). The pattern of response to divalent cations and to EDTA and ATP may be explained on the basis that $\mathrm{Ca}^{2+}$ acted as a cofactor in the place of $\mathrm{Mg}^{2+}$ when the latter was absent, but competed in its presence, and that EDTA and ATP were chelating agents. Thus in the absence of $\mathrm{Mg}^{2+}, \mathrm{Ca}^{2+}$ stimulated (Fig. 3a) and EDTA inhibited (Fig. $3 b)$. With added $\mathrm{Mg}^{2+}(5 \mathrm{mM}) \mathrm{Ca}^{2+}$ inhibited (Fig. 3a), whereas EDTA (Fig. 3b) and ATP (Fig. 5) stimulated at low, and inhibited at high (Fig. $3 b$ and Table 5) concentrations. However, the greater affinity of ATP for $\mathrm{Mg}^{2+}$ than $\mathrm{Ca}^{2+}$ suggests that there is another factor too, possibly the relative affinities of the enzyme for the two cations.

Various attempts have been made to explain how nucleotides enhance conjugation. Pogell \& Leloir (1961), considered that UDP- $N$-acetylglucosaminase and ATP stimulated $p$-nitrophenol conjugation by inhibiting UDP-glucuronic acid breakdown, via pyrophosphatase. Ogawa et al. (1966) showed that UMP and UDP inhibited this enzyme. Pogell 
\& Leloir (1961) suggested that nucleotides also had a direct effect on glucuronyltransferase because they stimulated guinea-pig microsomes in which pyrophosphatase was not detected. Hollmann \& Touster (1962) have now shown that it is present. Lester (1968) studied the effect of nucleotides on bilirubin conjugation and concluded that there was enhancement that could not be explained by inhibition of pyrophosphatase. Winsnes (1969) failed to activate bilirubin conjugation with UDP- $N$-acetylglucosamine but succeeded with four phenolic substrates. ATP was inactive. He attributed nucleotide (and detergent) activation to an allosteric effect. Rao \& Breuer (1969) found that UDP- $N$-acetylglucosamine did not affect an oestradiol-17 $\beta$ glucuronyltransferase from the cell sap of pig small intestine. The preparation contained no pyrophosphatase. Although they claimed that ATP (but not UDP) inhibited the transferase competitively with UDP-glucuronic acid, their data are unconvincing because of the scatter and small inhibition.

Our preincubation experiments (Table 4) strongly support the argument that stimulation of non-solubilized microsomes by UDP- $N$-acetylglucosamine was due to inhibition of UDP-glucuronic acid pyrophosphatase, and that it failed to stimulate the soluble preparation because pyrophosphatase was absent. A less probable explanation is that the transferase lost its sensitivity to uridine nucleotides as a result of solubilization. The stimulation of soluble enzyme by ATP (Fig. 5) was probably due to chelation of $\mathrm{Ca}^{2+}$. The very large effect on microsomes (Table 3 ) which probably had a different mechanism from that of UDP- $N$-acetylglucosamine, since they were more than additive, has not been examined.

In the soluble preparation UDP and UMP inhibited (Table 2). In spite of structural similarities to UDP-glucuronic acid competition was not competitive with this substrate (Fig. 4). The effect cannot have been due to chelation since the order of chelation capacity (UTP $>$ UDP $>$ UMP) is the opposite of the order of inhibition. Allosteric inhibition is a possibility.

The inhibition of soluble transferase by steroids was not produced at the aglycone substrate site. One of the inhibitory steroids, oestrone sulphate, could not be a substrate. This steroid, $3 \beta$-hydroxyandrost-5-en-17-one and stilboestrol, were 'apparently competitive' with UDP-glucuronic acid (Figs. 6, 7, 8). In view of the marked difference in structure, competition between steroids and UDP. glucuronic acid for a common site would appear to be improbable. There is another possibility, however, for Cleland (1963) has pointed out that the kinetic pattern of competitive inhibition merely requires combination of the substrate and inhibitor with the same form of the enzyme in the reaction sequence, and not necessarily at the same site. An 'apparent competition' then results from an inhibitor-activated conformational change in the protein which leads to decreased binding affinity for the substrate. Although the substrate and inhibitor sites could be visualized on a single protein, a protein consisting of several polypeptide chains is an alternative and possibly simpler explanation. The suggestion that steroids may alter glucuronyltransferase by an allosteric mechanism requires confirmation. It may have some general implication in the control of metabolism by steroids.

The finding that some steroids appear to inhibit competitively with UDP-glucuronic acid may be important in understanding jaundice in the newborn, for UDP-glucuronic acid and UDP-glucose dehydrogenase have been reported to be low in newborn and foetal guinea-pig liver (Brown \& Zuelzer, 1958; Dutton, 1959; Flodgaard \& Brodersen, 1967) and in human foetuses (Dutton, 1959). Lathe \& Walker (1958b) could not understand why pregnant women were not jaundiced if steroids inhibited transferase. However, in view of the competitive aspect the inhibition would be predicted to be much greater in the newborn when the 'competitor', UDP-glucuronic acid, was low.

There are high concentrations of steroids in foetal blood. At birth most of these steroids are either oestrogens or $3 \beta$-hydroxy- $\Delta^{5}$-steroids (Mitchell, 1967). The latter group are found mainly as sulphate conjugates. One $\Delta^{5}$-steroid, $3 \beta, 16 \alpha$ dihydroxyandrost-5-en-17-one, is particularly prevalent, having a concentration in cord plasma of about $360 \mu \mathrm{g} / 100 \mathrm{ml}$ (Easterling, Simmer, Dignam, Frankland \& Naftolin, 1966), or about $10 \mu \mathrm{M}$. The total $3 \beta-\mathrm{OH}-\Delta^{5}$-steroid sulphate concentration must be considerably higher than this and may approach the amount $(50 \mu \mathrm{M})$ at which concentration $3 \beta$-hydroxyandrost-5-en-17-one inhibited the rat enzyme by $20 \%$ (Table 6 ). $3 \beta$-hydroxyandrost-5en-17-one appeared, however, to be a more potent inhibitor than its sulphate or the $16 \alpha$-hydroxy derivative (Table 6). Thus in the newborn three circumstances may favour poor bilirubin conjugation; a small amount of transferase, large amounts of inhibitory steroids and probably inadequate UDP-glucuronic acid which intensifies the steroid inhibition.

The failure to observe a significant inhibition by $5 \beta$-pregnane- $3 \alpha, 20 \beta$-diol supports our conclusion (Adlard \& Lathe, 1970) that this steroid is unlikely to be the causative agent in so-called 'breast milk jaundice' (Arias, Gartner, Seifter \& Furman, 1964).

We thank the Medical Research Council for a Training Grant (B.P.F.A.) and a Research Grant (G.H.L.), and Dr D. G. Herries and Dr S. R. Stitch for helpful discussions. 


\section{REFERENCES}

Adlard, B. P. F. \& Lathe, G. H. (1970). Archs Dis. Childh. 45, 186.

Aldridge, W. N., Emery, R. C. \& Street, B. W. (1960). Biochem. J. 77, 326.

Arias, I. M., Gartner, L. M., Seifter, S. \& Furman, M. (1964). J. clin. Invest. 42, 913.

Bevan, B. R., Holton, J. B. \& Lathe, G. H. (1965). Clin. Sci. 29, 353.

Brown, A. K. \& Zuelzer, W. W. (1958). J. clin. Invest. 37, 332.

Cleland, W. W. (1963). Biochim. biophys. Acta, 67, 173.

Conney, A. H. \& Burns, J. J. (1961). Biochim. biophys. Acta, 54, 369.

Dutton, G. J. (1959). Biochem. J. 71, 141.

Dutton, G. J. (1966). In Glucuronic Acid, p. 185. Ed. by Dutton, G. J. London: Academic Press.

Easterling, W. E., Simmer, H. H., Dignam, W. J., Frankland, M. V. \& Naftolin, F. (1966). Steroids, 8, 157.

Fiske, C. H. \& Subbarow, Y. (1925). J. biol. Chem. 66, 375.

Flodgaard, H. J. \& Brodersen, R. (1967). Scand. J. clin. Lab. Invest. 19, 149.

Ginsburg, V., Weissbach, A. \& Maxwell, E. S. (1958). Biochim. biophys. Acta, 28, 649.

Graham, A. B. \& Wood, G. C. (1969). Biochem. biophys. Res. Commun. 37, 567.

Halac, E. \& Reff, A. (1967). Biochim. biophys. Acta, 139, 328.
Hollman, S. \& Touster, O. (1962). Biochim. biophys. Acta, $62,338$.

Hsia, D. Y-Y., Riabov, S. \& Dowben, R. M. (1963). Archs Biochem. Biophys. 103, 181.

Isselbacher, K. J., Chrabas, M. F. \& Quinn, R. C. (1962). J. biol. Chem. 237, 3033.

Jones, B. (1964). J. Pediat. 64, 815.

Lathe, G. H. \& Walker, M. (1958a). Biochem. J. 70, 705.

Lathe, G. H. \& Walker, M. (1958b). Q. Jl exp. Physiol. 43, 257.

Lester, R. G. (1968). Ph.D. Thesis: University of Leeds.

Lineweaver, H. \& Burk, D. (1934). J. Am. chem. Soc. 56, 658.

Lowry, O. H., Rosebrough, N. J., Farr, A. I. \& Randall, R. J. (1951). J. biol. Chem. 193, 265.

Mitchell, F. L. (1967). Vitams Horm. 25, 191.

Ogawa, H., Sawada, M. \& Kawada, M. (1966). J. Biochem., Tokyo, 59, 126.

Pogell, B. M. \& Leloir, L. F. (1961). J. biol. Chem. 236, 293.

Rao, G. S. \& Breuer, H. (1969). J. biol. Chem. 244, 5521.

Schliselfeld, L. H., van Eys, J. \& Touster, O. (1965). J. biol. Chem. 240, 811.

Schneider, W. C. \& Hogeboom, G. H. (1950). J. biol. Chem. $183,123$.

Tomlinson, G. A. \& Yaffe, S. J. (1966). Biochem. J. 99, 507.

Van Roy, F. \& Heirwegh, K. P. M. (1968). Biochem. J. 107, 507.

Winsnes, A. (1969). Biochim. biophys. Acta, 191, 279. 